\title{
Study on Opening and Closing Motion Law of Common Rail Injector Needle Valve
}

\author{
Ziwei ZHANG ${ }^{1}$ and Chunlong XU \\ China North Engine Research Institute, China
}

\begin{abstract}
The motion of common rail injector needle valve and the hydraulic process of fuel control circuit are studied by using simulation method. The simulation model is verified by comparing the injection rate curve. The results demonstrate that the lifting of the injector ball valve changes the fuel flow in the control chamber, leading to two different speed stages as the needle valve is opened. The seating of ball valve changes the clearance between the ball valve and the valve seat, and the needle valve closing motion curve slope remains unchanged. The increase of rail pressure affects the needle valve motion speed at the rapid opening stage. When the rail pressure reaches a certain valve, it no longer affects the motion characteristics of the needle valve. The change of fuel inlet hole diameter affects the needle valve rapid opening and closing movement. The change of fuel outlet hole diameter mainly affects the closing movement of needle valve.
\end{abstract}

Keywords. Injector, Needle Valve, Rail Pressure, Inlet Hole, Outlet Hole.

\section{Introduction}

Fuel injector is the core component of high pressure common rail system, and its performance directly affects the combustion and emission of diesel engine [1]. Although the injector performance continues to improve, there are still some problems in practical work, such as injection delay caused by slow response of the control valve, loose sealing caused by the contact friction between needle valve and valve seat, cavitation erosion to components caused by the internal flow of the injector hydraulic system, and poor injection consistency [2].

The control valve in the injector connects or cuts off the fuel circuit under the action of the solenoid valve and adjusts the control chamber pressure by changing the fuel flow rate in fuel control circuit, so as to change the force and control the movement of needle valve [3]. Thus, the hydraulic process in the fuel control circuit of injector can determine the opening and closing process of needle valve. The needle valve motion can affect the injection characteristics. Therefore, it is necessary to study the flow characteristics of fuel control circuit in the injector. In this paper, the onedimensional simulation model of injector is established by AMESim software to study the needle valve movement process and the fuel flow characteristics in the fuel control circuit.

${ }^{1}$ Corresponding Author, Ziwei ZHANG, China North Engine Research Institute, China; E-mail: 751334315@qq.com. 


\section{Model Establishment and Verification}

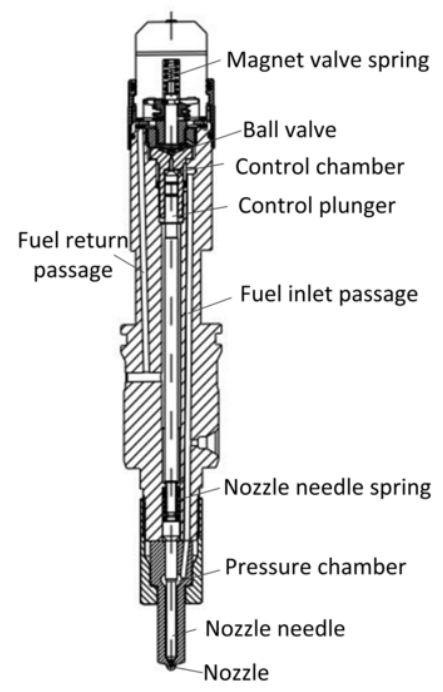

Figure 1. Common rail injector.

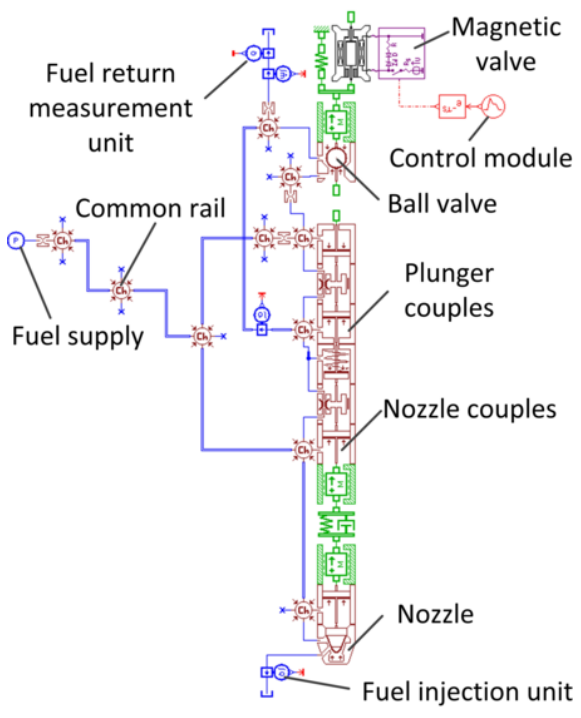

Figure 2. Simulation model.

Figure 1 shows the injector structure. Based on the injector demonstrated in figure 1, the simulation model which is shown in figure 2 is established by using AMESim. In order to verify the model, the fuel injection rate measured on the test-bed is compared with the simulation value. During the test, the high-pressure fuel pump operates at 800 $\mathrm{r} / \mathrm{min}$, the target rail pressure is set as $180 \mathrm{MPa}$, and the fuel injection rates with two different pulse widths of $0.8 \mathrm{~ms}$ and $0.9 \mathrm{~ms}$ are measured respectively. By comparing the simulation and test results, the error between the simulation results and the test results is within $5 \%$ in figure 3 , which can verify the model correctness.

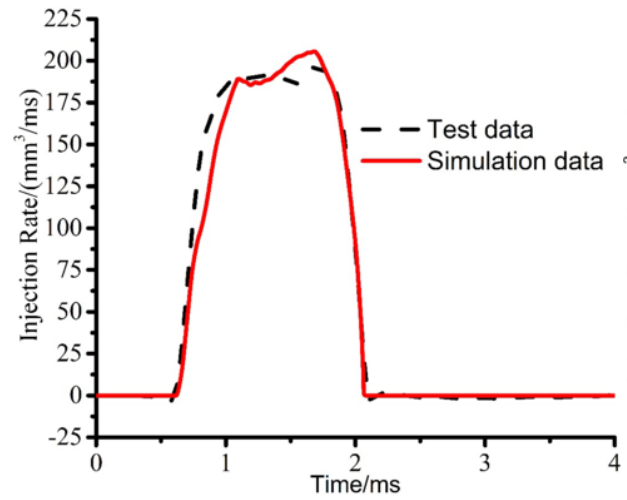

(a) Injection rate at pulse width $0.8 \mathrm{~ms}$

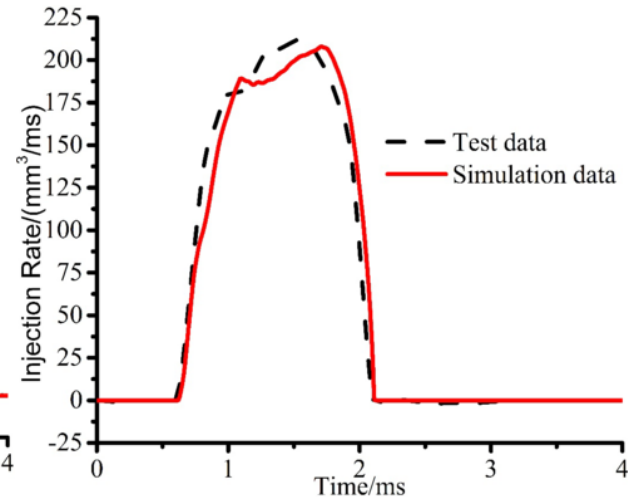

(b) Injection rate at pulse width $0.9 \mathrm{~ms}$

Figure 3. Simulation verification. 


\section{Results and Analysis}

\subsection{Needle Valve Movement Law}

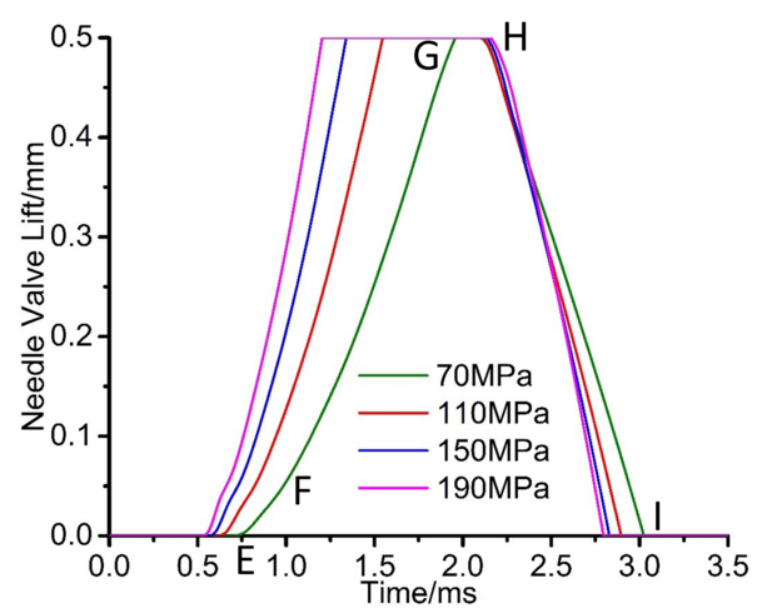

Figure 4. Needle valve lift curve.

The needle valve motion curve is illustrated in figure 4. As shown in figure 4, mark the turning points in the needle valve lift curve as E, F, G, H and I; Point E corresponds to the needle valve opening time, point $F$ is the turning point in the needle valve opening process, point $G$ is the time point when the needle valve reaches the maximum displacement, point $\mathrm{H}$ is the time point when the needle valve starts to close, and point I is the time point when the needle valve is completely closed and fuel injection terminates. Therefore, the needle valve motion curve is divided into four periods, namely EF, FG, GH and HI, in which EF section is the initial opening stage of needle valve and FG section is the rapid opening stage. The opening speed of EF and FG sections is different. GH section is the fully opening stage and HI section is the closing stage.

The change of fuel outlet hole flow area and the flow area between the ball valve and the valve seat produces two motion stages during the needle valve opening process. The change of the flow area between the ball valve and valve seat mainly leads to one motion stage during the needle valve closing process [4].

Figure 5 shows the needle valve speed curve with the operating condition $180 \mathrm{MPa}$ rail pressure. In figure 5, the needle valve speed in the EF section gradually increases, and its speed in the FG section further increases, but the increasing slope is different from that in the EF section. The needle valve reaches the maximum lift in the GH section, and its motion speed is zero. In HI section, there is a sudden change in velocity at turning point $\mathrm{H}$ and a downward acceleration. At turning point $\mathrm{I}$, the velocity changes, then the velocity decreases to zero, and the acceleration changes from negative to zero.

From the above analysis, we know that the needle valve speed changes from zero to a specific value at the turning point $E$ due to the sudden opening of ball valve, resulting in the sudden reduction of control chamber pressure. The plunger and needle valve produce instantaneous acceleration under the combined force of hydraulic pressure and spring preload [5]. Turning point $\mathrm{F}$ is the transition point of acceleration 
change, which is due to the conversion of the fuel outlet hole flow rate and the fuel flow rate between the ball valve and valve seat after the ball valve is opened to a certain stage. The speed at turning point $\mathrm{G}$ changes from the maximum value to zero due to the sudden change of speed caused by the collision with the limit block after the needle valve reaches the maximum lift. Turning point $\mathrm{H}$ is the transition point at which the speed changes from zero to a certain value. Turning point $I$ is the transition point at which the speed changes from a certain value to zero.

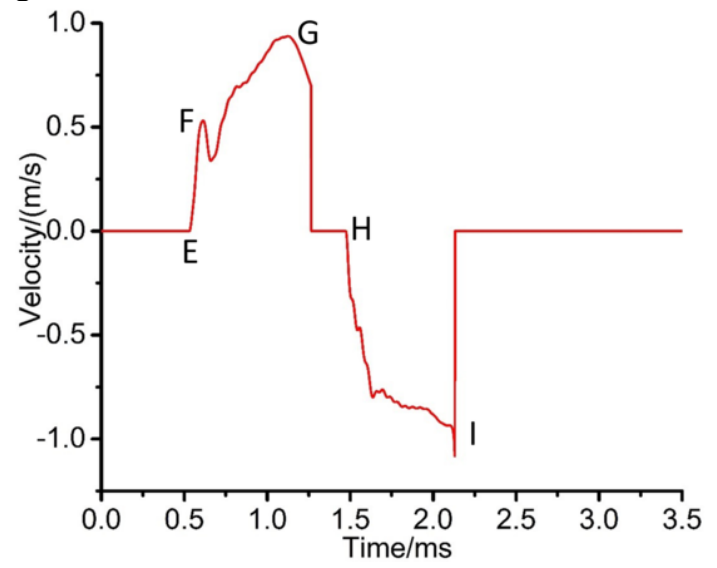

Figure 5. Needle valve velocity curve.

\subsection{Influence of Rail Pressure on Needle Valve Movement}

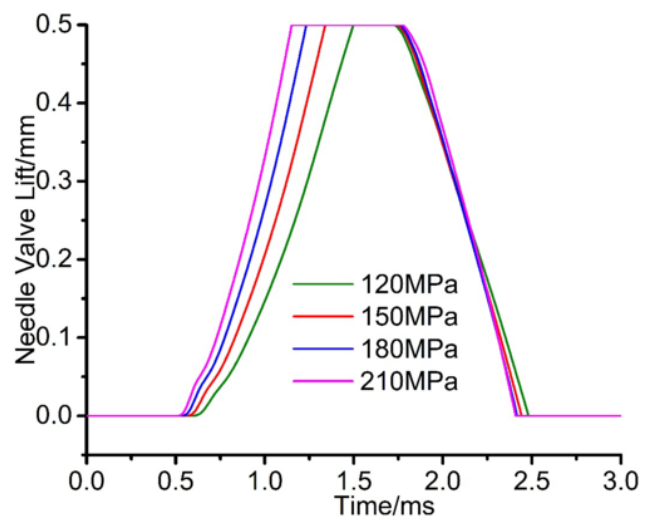

Figure 6. Needle valve lift varying with rail pressure.

With the operating condition of $120 \mathrm{MPa}, 150 \mathrm{MPa}, 180 \mathrm{MPa}$ and $210 \mathrm{MPa}$ rail pressure, the needle valve lift curve is demonstrated in figure 6. As shown in figure 6, the needle valve opening time gradually increases with the decrease of rail pressure, while its closing time gradually decreases with the increase of pressure, which illustrates that the needle valve movement time decreases with the increase of pressure. In addition, with the change of rail pressure, the curve slope of needle valve at initial opening stage and closing stage basically remains unchanged, which demonstrates that the change of rail pressure has no effect on needle valve initial opening stage and closing stage. With the increase of rail pressure, the slope of needle valve rapid opening 
stage gradually increases, which indicates that the movement speed of needle valve increases.

\subsection{Influence of Inlet Hole on Needle Valve Movement}

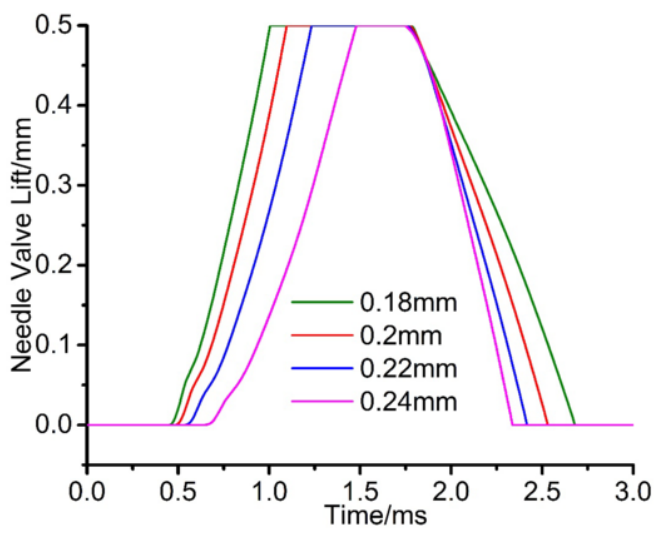

Figure 7. Needle valve lift varying with inlet hole diameter.

With the operating condition of $180 \mathrm{MPa}$ rail pressure and $0.3 \mathrm{~mm}$ fuel outlet hole diameter, the needle valve lift curve corresponding to four different fuel inlet hole diameters $(0.18 \mathrm{~mm}, 0.2 \mathrm{~mm}, 0.22 \mathrm{~mm}$ and $0.24 \mathrm{~mm})$ is shown in figure 7 . As shown in figure 7 , the needle valve opening time gradually increases with the increase of fuel inlet hole diameter, while the closing time gradually decreases with the increase of fuel inlet hole diameter, which indicates the needle valve movement time decreases with the increase of fuel inlet hole diameter. With the increase of fuel inlet hole, the curve slope at the initial opening stage of needle valve remains unchanged, the slope at the rapid opening stage decreases, and the curve slope at the closing stage shows an upward trend. Therefore, the change of fuel inlet hole mainly affects the needle valve rapid opening and closing stage.

\subsection{Influence of Outlet Hole on Needle Valve Movement}

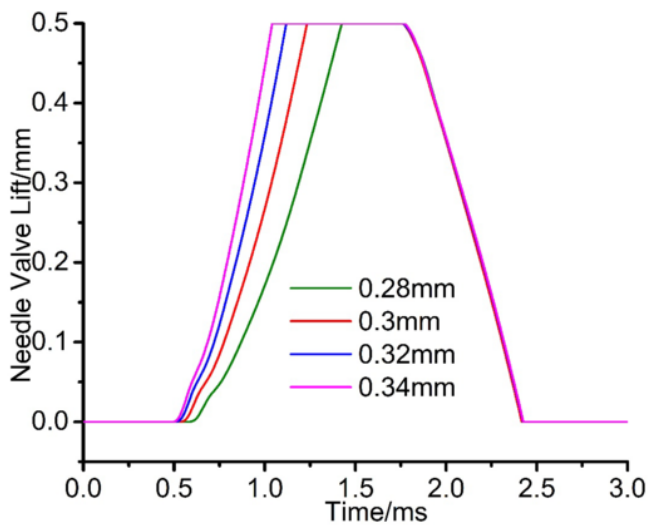

Figure 8. Needle valve lift varying with outlet hole diameter. 
With the operating condition of $180 \mathrm{MPa}$ rail pressure and $0.22 \mathrm{~mm}$ fuel inlet hole diameter, the needle valve lift curve corresponding to four different fuel outlet hole diameters $(0.28 \mathrm{~mm}, 0.3 \mathrm{~mm}, 0.32 \mathrm{~mm}$ and $0.34 \mathrm{~mm})$ is shown in figure 8 . As shown in figure 8 , the needle valve opening time gradually increases with the decrease of fuel outlet hole diameter, while its closing time remains unchanged, which indicates that the needle valve movement time decreases with the decrease of fuel outlet hole diameter. With the increase of the fuel outlet hole diameter, the curve slope at the needle valve initial opening stage remains unchanged, the curve slope at the rapid opening stage increases, and the curve slope at the closing stage remains unchanged. Therefore, the change of the fuel outlet hole mainly affects the rapid opening stage of needle valve.

\section{Conclusion}

In this paper, the motion law of injector needle valve is studied by simulation method. Through the analysis, the movement process of the needle valve is divided into four movement stages, namely, initial opening stage, rapid opening stage, fully opening stage and closing stage.

The slope of needle valve rapid opening section is larger than its initial opening section. The needle valve closing stage is determined by the flow area between the ball valve and valve seat. The greater the mass flow of fuel inlet hole, the greater the needle valve movement speed.

The change of rail pressure mainly affects the needle valve rapid opening stage. With rail pressure increasing, the needle valve movement speed increases at the rapid opening stage.

When the fuel outlet hole diameter remains unchanged and the fuel inlet hole diameter is changed, it mainly affects the needle valve rapid opening stage and closing stage. With the fuel inlet hole diameter increasing, the slope of needle valve in the rapid opening stage decreases, while the slope of needle valve in the closing stage increases.

When the fuel inlet hole diameter remains unchanged and the fuel outlet hole diameter is changed, it mainly affects the needle valve rapid opening stage. With the increase of fuel outlet hole diameter, the slope of needle valve rapid opening stage increases, while the slope of the needle valve closing stage is almost unchanged.

\section{References}

[1] Amirante R, Coratella C, Distaso E, Rossini G and Tamburrano P. Optical device for measuring the injectors opening in common rail systems. International Journal of Automotive Technology. 2017 Aug;18(4):729-742.

[2] Haoyuan MA, Tong Z, Qingsong AN, Yuhao T and Yue X. Visualization experiment and numerical analysis of cavitation flow characteristics in diesel fuel injector control valve with different structure design. Journal of Thermal Science. 2021 Mar;30(01):76-87.

[3] Liu HC, Lee HJ and Lee J. Design of a double-path magnetic circuit structure hybrid fuel injector considering demagnetization characteristics. 2019 Jan; 48(3):1421-1428.

[4] Mohebbi M, Aziz AA, Hamidi A, Hajialimohammadi A and Hosseni V. Modeling of pressure line behavior of a common rail diesel engine due to injection and fuel variation. Journal of the Brazilian Society of Mechanical Sciences and Engineering. 2017 Jan;39(3):661-669. 
[5] Lee YJ, Lee $\mathrm{CH}$. An uncertainty analysis of the time-resolved fuel injection pressure wave based on BOSCH method for a common rail diesel injector with a varying current wave pattern. Journal of Mechanical Science and Technology. 2018 Mar;32(12):5937-5945. 